CAse nCxr. D. N., aged about 55 , had been under my care for many years, for an intense neuralgic condition of the face and head, apparently originating in an injured eye. The other eye was excessively weak, and he was quite unable to work. He had undergone all linds of treatment at my hands and under the care of other surgeons, and among the means used may be reckoned: blisters, leeches, mercury, setons, iron, quinine, opium, and ultimately, the long issue in the scalp, which latter relieved him much. I gave him some chloroforn, with the intention of removing his eye while he was insensible, but his pulse became so intermittent that I was obliged to operate without. He struggrled a good deal, and it was not an easy case, as the aperture of his eyelids was very small. He recovered and was able to return to his work and he grew stouter, but he had now and then an attack of neuralgic pain, although not comparable in severity to his former sufferings.

CaSE DCxx. C. H. aged 15. The right eye, which had been injured by a piece of crockery, and had given rise to much pain and intolerance of light and dimness of sight in the other eye, was removed by me in the usual way, under chloroform. She went out cured in a very short time.

CASE DCXXI. S. C. aged about 56. The right eye was removed in consequence of long standing disease involving the cornea and iris. I found considerable ditficulty in this case also, in consequence of the small aperture between the lids. The patient did remarkably well.

CASE DCXxrr. H.T. aged 55. This patient was nearly blind from internal disorganisation of the right eye. Her left eye was almost useless to her from the dimness and intolerance of light, and the disease in both had been of long standing. She refused to take chloroform, and therefore I operated without. She recovered well, and has retained the use of the other eye, which was rapidly failing before the operation.

The great peculiarity in this case was the condition of the eye. The cornea was opaque, rough, and yellow; the lens hard and also opaque was loose in the anterior chamber; the pigment internally had disappeared, and occupying the position of the choroid was a thin delicate shell of bone, brittle and hard and semi-transparent in its nature.

This ossification of the choroid coat has not been no. ticed much by authors, obviously on account of the want of opportunity of examining many specimens which existed before this operation became established. Gross, in his very comprehensive volume on pathological anatomy, gives an account of this state, but with that exception I have seen no notice of it.

The following case, the last I have to narrate of ex tirpation of the eye, is another instance of this nature.

CASE DCXXmr. G. H., aged 35, lost his left eye by an injury with a peg-top, when a young boy, and a few years before I saw him he had undergone an operation for the removal of the opaque lens in this eye. The operation did not succeed and constant pain and irritation with great intolerance of light followed it, and he was unable to attend to business. I removed the remains of the left eye, and he was better the next day than he had been for years, and the result of the case was very satisfactory.

There was partial collapse of the globe, and a folding of the sclerotic. The posterior part of the choroid was firmly ossified, with a small round hole in it, where the optic nerve was connected with the retina. The bony substance which replaced the choroid was thicker and firmer than in the former case, where it formed a delicate shell.

REMARKS. The instruments required for this operation are a curved scissors, a scalpel, a forceps, a strabismus hook, and the wire speculum. The globe only is to be removed, the muscles being divided close to the sclerotic, and no section of the outer commissure of the lids, re quired for the removal of cancerous and other tumours of the orbit, is necessary. The case is clearly one winere chloroform is advisable, although one of my patients (Case 630) preferred to submit without. After touching with a sharp scalpel round the conjunctiva, about the eighth of an inch from the edge of the cornea, I have found it convenient to raise the recti muscles one after the other upon a strabismus hook and divide thern, when the globe starts forward and the division of the optic nerve and other posterior connections is readily accomplished.

\section{CASE OF STRANGULATED HERNIA TREATED SUCCESSFULLY BY THE INVERTING METHOD.}

By G. Pound, Esq., Odiham.

Mrs. E., aged 50, has been the subject of hernia (oblique inguiual) of the right side for many years. She has also prolapsus uteri. She has at different times suffered very much with severe symptoms, as sickness and pain; and the hernia bas often been irreducible by her own efforts for some days. These attacks have lately become more frequent. She first became a patient of mine in March last. At that period she had sickness, constipation, pain in the abdomen, and the hernial tumour was as large as an orange, not very tender, but could not be returned. Under the use of opium and an enema, the symptoms subsided, and she was able to effect reduction herself. A second attack occurred in May; the same treatment was pursued with a like successful result.

I was called to the case for the third time on Monday the 22 rid July. I saw my patient at 6 P.s. She stated that, feeling poorly the past week, she had taken two "antibilious" pills; the last pill she had taken on the previous Saturday night, and her bowels were moved on Sunday morning. She had been very sick; and the hernial protrusion had occurred during violent retching, and had existed since midday on Sunday. The sicliness was, when I saw her, very troublesome; the countenance was anxious; the belly rather full and distended. The taxis failed to make any impression on the hernia. The tongue was clean; pulse 108 , weak. A pill con. taining opium was ordered to be taken every four hours, with two minims of hydrocyanic acid in mixture, and an injection to be administered immediately.

July 23, 10 A.n. The sickness was the same. The injection was returned immediately last evening. There was no action of the bowels. 'The tumour in the groin was in the same state. The opium and mixture were continued; and the enema was repeated; pulse 96.

6 P.sr. The husband came to my surgery, and informed me that the injection had acted; that she had not been sick since my visit in the morning; that the hernia was smaller; and that she had had a little sleep. My experience of the case led me to hope that the result would be as fortunate as on former occasions.

July 24,11 A.M. I found that the account given last evening by the husband of the patient was too fuvourably coloured. The sickness had now been very trouble. some since 3 A.nr. A little gruel tinged with fæcal matter was shown to me as the stool. The tumour had diminished nothing in size, and was a little ter,der on handling. About the neck there was considerable thickening. The tongue remained clean; pulse 96 . 'The countenance was somewhat anxious; the belly felt distended, but was not very tender. The enema was repeated; and she was ordered to take a grain of opium directly and another grain an hour afterwards.

3 P.Ir. Considering the probability to be strong that 169 
an operation would be ultimately required, I asked my neighbour Dr. Scott, to see the case with me. The injection had returned tinged with fæcal matter. She had not vomited since my last visit. The taxis, tried both by Dr. Scott and myself, failed to reduce the hernia. We now introduced a long tube a considerable distance, and injected a large quantity of warm water; this soon returned coloured, and at the same time she had a fit of vomiting. On her return to bed, the taxis was again applied, but with no better result. Still we considered the symptoms did not call for operative interference at present. Ice was now applied to the swelling, and two grains of opium given at 5 P.Mr. We did not, either of us, consider that the warm-bath or chloroform were called for in the case. With regard to the former, the patient was weakly; and we felt doubtful about the advisability of administering chloroform from certain chest symptoms.

7 P.M. We again met in consultation. She had had a comfortable nap; and had not vomited since our last visit. No action of the bowels had taken place. The tumour was precisely the same.

I now proposed to Dr. Scott and to the patient to try the plan of inversion lately recommended by Mr. Jessop of Cheltenham; but the patient seemed unwilling to allow resort to any further measures, and expressed also her determination not to allow the operation, even if we ultimately decided that it would be necessary. Sickness was now again felt; and vomiting occurred whilst we were down stairs consulting and advising the husband. The vomited matter, on inspection, was found to be ster coraceous. We both felt strongly that further delay would not be justifiable; and we urged the absolute necessity of our being allowed to use the means still a our disposal. The patient at last consented; and we proceeded to "invert" her. We placed a chair upside down by the side of the bed, so that the seat projected under it, and the legs with the back of the chair formed an inclined plane from the bed to the floor; on this was placed a long bolster. The patient was now taken by the shoulders, and brought to the side of the bed; the head and shoulders were gently lowered till they rested on the floor on pillows, whilst the legs remained on the bed. This plan is much more delicate, I fancy, than the one of raising the patient by placing the legs over the shoulders of an attendant. The first moment of the application of the taxis was an anxious one; and, I may add, one of curiosity. Will it answer? Yes; in less time than it takes me to write this account. First, a sensation of adhesions giving way; then a gurgling; and then a complete disappearance of all hernial pro. trusion.

The experiment was successful; the relief speedy and complete. An hour afterwards she had a copious eva cuation, and at the same time a little stercoraceous vomiting. She then took 30 minims of Battley's sedative; since which she has experienced no bad symptom whatever.

Antiquity of the Water-Clre. We have just noticed in the writings of Celsus, in the first century, what was, perhaps, the earliest application of the water-cure. The administration was quite up to the modern style of heroichydropathy. 'The disease in which he recommends it is hydrophobia, and the following is the method of applying the remedy: "Throw the patient unexpectedly into a fish pond, and, if he be unable to swim, keep him for some time immersed, so as to make him swallow a portion of water, and then raise him out of it, alternately immersing and emerging him; but, if able to swim, he should be kept in the same manner at times immersed by force, so as to be surfeited with water; by which means both the thirst and the dread of water will be effectually subdued." (Phil. Med. Rep.)

\section{Cransactions of âdrametres.}

LANCASHIRE AND CHESHIRE BRANCH. CASE OF RUPTURED PERINEUM DURING UNASSISTED LABOUR.

By Thomas Skinner, M.D., Obstetric Physician to the Liverpool Dispensaries; Fellow of the Obstetrical Society of London, etc.

[Read June 6.]

Mrs. R., aged 23 years, a primipara, was taken in laboun about eleven o'clock of the evening of Oct. 29th last but as the symptoms were trifling she did not send for me. About half-past six o'clock on the following morn-w ing, very smart and strong expulsive pains suddenlycame on, and before the messenger had got half way too myself or any other accoucheur, she had given birth too a female child. On reaching the house, I found that my friend Mr. David Paterson had arrived before me. directed my attention to the fact that the perineum was severely ruptured. On examination, we found that the laceration extended from the fourchette up to the recto vaginal septum, which latter, with the sphincter ani, re-s mained entire. The rupture included the entire thickness of the perineum, extending a considerable distance $\overrightarrow{00}$ up the vagina (the mucous membrane only) and through the skin and mucous membrane of the anus to about half an inch or so within the orifice of the anus. 'There waso some bleeding, but no more than might have been expected. In every other respect the labour was natural I think it important to state that the patient was healthy and natural as regards embonpoint; that the propor tions of the pelvis and soft parts were normal; that the length of the child was eighteen inches, while the fronto-occipital and corono-occipital circumferences of its head measured twelve inches either way.

Operation. Within a few hours of the occurrence of tho? accident, and with the kind assistance of Mr. Paterson, I placed the ruptured parts together again with two deep "needle sutures" and two superficial interrupted ones, all of which were removed on the morning of the fifth day, when Mr. Paterson and I had the satisfaction: of seeing the rupture healed in its entirety; and so perfect was the liue of union that it was scarcely pos sible on the tenth or twelfth day to trace the locale of the lesion by the cicatrix.

I lave little hesitation in stating that the "needle suture," as invented or reintroduced by my friend Dr.윽 Aveling of Sheffield, is much less irritating, better borneN by the patient, and is in every respect much to be pre-or ferred to the silk quilled suture. The thickness of the suture which I used was sixteen on the Parisian wire을 gange; they are manufactured by Messrs. Cocker Brothers of Sheffield, and sold by Mr. Henry Aitken, cutler, York, who supplied me. I think it proper to add that I bent the wire before introducing the needle point, $\sigma$ that I passed each end through a smooth flat splint of wood, that I fixed them by means of pierced duck shot, and then removed the extremities. I would further add, (D) that the sutures ought to be applied only sufficiently? tight to bring the deep parts of the laceration into apposition, greater tightness will only do harm, by cutting tissue and causing congestion and irritation; it is quite $\frac{7}{(\mathbb{D}}$ simple, if necessary, to retighten the sutures as the? subsidence of the congested state of the perineal struc- $\mathbb{D}$ tures takes place.

REMARKS. Denman has said, that when women wero delivered without assistance, he had not in any case ob-O served considerable laceration (5th edit., p. 79). If응 this case teaches anything, it teaches most clearly that the whole tissues of the perineum may be ruptured bye . . 